\title{
Learning Programming with Robots: A Study on Students' Participation in a Virtual Community of Practice
}

\author{
Elci Alcione Santos*, Luiz Guerreiro Lopes \\ Faculty of Exact Sciences and Engineering, University of Madeira, Penteada Campus, 9020-105 Funchal, Madeira Is., Portugal
}

Received August 26, 2019; Revised November 22, 2019; Accepted December 04, 2019

Copyright (C) 2020 by authors, all rights reserved. Authors agree that this article remains permanently open access under the terms of the Creative Commons Attribution License 4.0 International License

\begin{abstract}
Nowadays, students learn from the world through a variety of physical and virtual spaces. As one of the priorities of the 21st century is to develop capacities associated with computational thinking and digital literacy, the use of robots in the teaching of programming is becoming more and more usual, since it promotes the development of problem solving, communication and teamwork skills. The purpose of this paper is to analyse and discuss the concept of participation in a virtual community created for the learning of programming with robots. Based on the situated learning theory and the underlying concepts of communities of practice, as well as the effects of technology thereon, we seek a better understanding of learning in these virtual spaces.
\end{abstract}

Keywords Participation, Communities of Practice, Educa-tional Robotics

\section{Introduction}

Nowadays, as we live in an interconnected global economy, to work connected with people from different cultural backgrounds is a ubiquitous necessity. In educational establishments, people are looking for new ways to meet the demands of the contemporary world and to innovate in teaching and learning contexts, what has become more complex as students learn through a variety of physical and virtual spaces.

Increasing development in technologies and the Internet, with their communication tools, has contributed to the creation of groups of individuals linked by non-formal relationships, but with common interests. These groups, linked in a network, make up the so-called virtual communities [1], which provide adequate space for the collective construction of knowledge, thus placing emphasis on the social nature of learning.

The literature presents a diversity of studies and projects (as, e.g., $[2,3])$ that have been developed in those online collabora- tion spaces, whether to conduct joint research, to create multimedia products, or to learn about the most varied topics.

One of the priorities of the 21 st century is the development of capabilities associated with computational thinking and digital literacy. The learning of programming has been a topic of interest of the school institutions $[4,5]$. Virtual learning environments have been developed (see, e.g., [6]) and several tools have been used to teach programming.

Robots has been increasingly used in the teaching of programming, since they facilitate the development of problem solving, communication and teamwork skills, and promote independence, imagination and creativity.

With this in mind, this article intends to analyse and discuss the participation of individuals in the community that originated from the Virtual DROIDE Project [7], which was created with the aim of contributing to the understanding of learning, in particular of Informatics and Mathematics, within a virtual context, using robots as mediating elements of that learning.

\section{Materials and methods}

It is challenging to convey in a few pages the whole experience of an investigation, with all the rigour and the nuances of qualitative data analysis, and at the same time avoiding excessive simplification. For this reason, only a small part of the project's research results will be described in this and the following sections.

\subsection{Motivation and objectives}

The need to understand how students learn in a non-physical space, the relationships that are established, the role of the teacher, the role of the students, how they learn to program, and the contribution of the use of robots in learning concepts of programming and mathematics, are some of the questions that were intended to answer when proposing the Virtual DROIDE Project. 
Since participation is fundamental for the construction of identity and the realization of learning, this study aims to analyse and discuss the participation of individuals in the Virtual DROIDE community.

\subsection{Research methodology and questions}

The research methodology adopted in the Virtual DROIDE Project was of a qualitative and interpretive nature, using participant observation as data collection method, and following the underlying principles of the Situated Learning Theory $[8,9]$, what has as a cornerstone the relationship between learning and the social conditions where it occurs.

The data collected and analysed in the study emerged from practice, consisting in particular of textual documents, graphics, images and computer animations produced by the participants and made available on Microsoft's SkyDrive cloud storage service (currently known as Microsoft OneDrive), as well as videos of some virtual meetings and the final in-person meeting.

The unit of analysis in this research was formed by people in action, having been examined in the dialectic of situated learning theory with the practices, as it is in the context of activities that people build on concepts that are transformed as people get related to each other. The meaning, understanding and learning are all defined in relation to the contexts of activity, mediated by the different experiences and perspectives of the co-participants.

\section{Virtual communities of practice}

The study of virtual communities, in this article, has as its basis the theory of situated learning in communities of practice (see, e.g., $[8,9,10,11,12]$ ).

The term "community of practice" was first used by Jean Lave and Etienne Wenger in the 1990s to describe learning through practice in the workplace. For these authors, the acquisition of knowledge is in the relationship of individuals with the community and happens when they participate in communities of practice. Participation refers to the process of taking part and has an intrinsically social sense, because even when undertaking a task individually, there is a proper scenario, which is public, as well as the implication of the peers in this process, which suggests both action and connection. The notion of community of practice refers to a social process of negotiating skills in a domain over time [13].

According to Wenger et al. [11], a community of practice presents three fundamental elements that distinguish them from other communities: a domain of knowledge that defines a set of issues, a community of people who care about that domain, and a shared practice that members of that community develop to be effective in that domain.

In turn, a virtual community of practice $(\mathrm{VCoP})$ requires more than simply shifting a community of practice into a virtual environment. Technological infrastructures must be created to support the functioning of virtual communities of practice to overcome obstacles that do not occur in communities of practice in general. These obstacles include the time to know and communicate, the size (as it may grow with new elements and involve different locations), the membership (as the members can participate in several communities), and the culture (since the members have different cultures) [14].

Communities develop over time without a predefined endpoint. They often start with attempts, with modest technological resources and only an initial perception of why they are together [15].

\section{Project description}

The Virtual DROIDE Project, previously mentioned, is described briefly below. The characterization of the participation in the community of practice created within its domain will be made in the next section, in light of the theory of situated learning, analysing to that end some of its aspects, including the discussion of meaning and patterns of practice, as well the reasons for participating and the forms of participation.

The project was created with the aim of contributing to the understanding of learning in a virtual context, especially in Informatics and Mathematics, using robots as mediators of such learning [16].

The project team, coordinated by the first author at the University of Madeira, was comprised of high school students from three distinct regions of Portugal (North and Centre of the country's mainland, and Madeira Island), and tutor teachers from the same locations.

The virtual groups were formed by at least one student from each location. The public disclosure of the Virtual DROIDE Project among students and the selection of those who were interested was the responsibility of tutor teachers, each member having received a LEGO ${ }^{\circledR}$ Mindstorms ${ }^{\circledR}$ robot kit, an updated copy of the DROIDE MLP multi-language programming platform [17, 18], a list of eight challenge problems, and a printed paper pad with dimensions of $100 \mathrm{~cm} \times 80 \mathrm{~cm}$ created specifically for the development of the proposed activities.

The elaboration of the challenge problems took into account certain aspects and requirements:

- the challenge problems must be computational in nature, but mathematically oriented;

- they should explore the proximity between the areas of Mathematics and Informatics;

- they should promote an approximation of the mathematics of school textbooks to real-life mathematics and, finally,

- they should convey the idea that complex problems can often be broken down into simpler problems.

During the project development, the student groups, each supported by a tutor, met virtually twice a week for about two hours, usually at night, because this was the period during which everyone had greater availability.

The virtual sessions took place using Messenger and, when video communication was needed, using the ooVoo video conferencing tool (discontinued at the end of 2017). All sessions 
were recorded for later analysis, including the extra meetings held by groups outside the schedule.

In order to create an additional motivation, a competition with rules of participation was established. A set of context requirements and constraints related to the robot construction and the challenge problems were defined, aiming to organize the practice in the context of the project.

Each challenge problem had a score associated with its degree of difficulty. At the end of three months (the period established for the conclusion of the project), all participants met at the University of Madeira for the final competition, where they had the opportunity to get to know each other in person.

\section{Participation in the virtual commu- nity of practice}

According to Lave and Wenger [8], learning is an integral part of social practice derived from real-world experience. In other words, learning is not just another process within practice, but rather an inseparable and central feature of that practice. For those authors, social practice is developed in communities of practice, and they define community of practice as "a learning partnership among people who find it useful to learn from and with each other about a particular domain. They use each other's experience of practice as a learning resource. And they join forces in making sense of and addressing challenges they face individually or collectively" [12].

In educational institutions, the physical spaces, the colours of the walls, the arrangement of furniture and the places where students and teachers circulate reflect their work philosophy, and students are left to demonstrate their differences in the clothes they wear and their manner of speaking and acting. In these differences it is possible to recognize some of the components of interaction considered important in the theory of communities of practice such as presence and face-to-face interaction.

Virtuality leads to the loss of some of these important components of interaction, including non-verbal elements that contribute to the meaning of messages [19]. In the virtual world, it is on the screen that knowledge is shared, and new forms of language and culture are developed, being that learning is built in online communities through collaborative activities. Adjusting to this new type of activity, which implies being alone in front of a computer solving problems in a virtual group, although it may motivate some, certainly discourages others.

In the Virtual DROIDE community, one of the members, upon his integration into the project, mistakenly understood that the work to be developed in each of the groups would be essentially on-location, which would allow for face-to-face interaction with colleagues from the same location, and that virtual communication would only occur between such groups. Not feeling as comfortable only with virtual interaction, this eventually set him on a trajectory away from the community. For others, it was precisely the virtual component that motivated them to participate, making them follow a trajectory in the opposite direction, into the community, because they intended to become full participants.
It is imperative to point out that a trajectory that leads out the community, such as that described previously, can also lead to the establishment of new relationships and the development of a new view of the world, of the community of which he was a part of and himself [10] and therefore cannot be viewed as negative.

\subsection{Negotiation of meaning and practice patterns}

Practice in a virtual community presents distinct features to those that occur in typical classroom situations. The manner of acting and negotiating, as well as the manner of expressing ideas and feelings is different to those commonly used in educational institutions.

Grounded on those differences, the challenge problems proposed in the project were structured taking into account certain requisites and restrictions in terms of context, namely:

- the pad should be unique, to mark the spaces equally;

- the robot should be built with the basic kit, so that the conditions were the same for everyone;

- LEGO's proposals could not serve as a model, thus forcing the creation of the robot;

- a single robot should be able to accomplish all the challenges, so that the work would be developed as a group and not divided among its members;

- the problems should be arranged by level of difficulty;

- the list of challenge problems should be simple and unambiguous so as not to allow differing interpretations;

- problems should have a single solution, but different forms of resolution;

- the solutions could not be subjective, so as to enable verification of the solutions obtained through the robot;

- one of the challenge problems would have to be mechanical in order to force the robot to move an object and, finally,

- the contents involved should be limited to those discussed in the disciplines of secondary school Mathematics and Informatics, so as to allow participants to develop competencies in these areas.

The demands and limitations laid down by the project meant that each participant had moments of intense experience of negotiation. How to build the robot? What is the challenge problem to solve? What topics to investigate? What is the better way to solve the problem? To meet on the Carnival holiday? These and other issues that generate the various moments of negotiation not only led to situations of mutual agreement between the parties, but, more than that, they were important moments for practice development.

Wenger [10] conceptualizes practice as a process of experiencing and engaging in the world in a significant manner, further stating that to participate in the world is above all a process of negotiation of meaning that involves much more than 
language or direct interaction with other human beings, being a continuous process that always creates new conditions for further negotiations and meanings. The desire to become a particular person in a social context is what drives the negotiation of meanings [13].

The following dialogue illustrates one of the moments of negotiation between the participants in a virtual session, where it was necessary to define the programming language that they were going to use and the implications of choosing one language or another.

Mark: You can use Visual Basic if you want. It's much easier and simple than $C$.

Kevin: Is it much different from $C$ ?

Mark: It's like Portuguese and Spanish. You can't talk well but you can understand it.

Fred: Does anyone know Pascal?

John: I know it very well!

Fred: It'd be cool if you could compare.

John: Pascal is a nicer language to the user, but much slower. $C$ is less pleasant but more efficient.

The entire course from the choice of programming language to the construction of robot programs to materialize the solutions for the proposed challenge problems was a continuous process, which shaped new contexts for further negotiations of meaning. According to Wenger [10], negotiation of meaning involves the interaction of two processes, participation and reification. The programs developed in the project, product of this participation process, resulted in the reification of practice.

Each of the three groups interpreted the problems and formulated and described solutions for them in different ways, as the negotiation of meaning is a process consisting of various elements which, in turn, ultimately affect themselves [10]. Therefore, even if leading to the same results, the developed programs were different, because both the robots that were built as well as the participants were not the same, all had distinct experiences and histories of participation in that practice.

The strategies used by each group to achieve the desired results were also different. One group, at the tutor's suggestion, started by using a flowchart to structure thinking. According to Nason and Woodruff [20], symbols, schemes, diagrams, etc. are external mathematical representations that aim to represent a certain mathematical "reality", act as stimuli in the senses, and are often embodiments of ideas or concepts.

Naturally, other forms of representation arose, one of the them being Adobe Flash (now known as Adobe Animate) animations and simulations, as the following dialogue indicates, and these animations became an important tool for the desired understanding, since, as Wenger [10] states, the reification of an activity made using a good instrument amplifies its effects and makes it easier. Moreover, the repetition of the adopted procedures creates a certain pattern in negotiation of meaning, thereby giving rise to significant experiences.

Michael: I suggest 7. What do you say Ben?!
Ben: For me 7 is OK, because we still don't know how to solve number 2.

John: OK, go to 7. Thursday I'll present a proposal for the second straight across and present the algorithm.

Michael: OK. I'm back! I SkyDrive for at least one of my SWF suggestions.

Another pattern that became apparent was the way in which to start programming the solution for a new challenge problem. In one group, each of the members independently elaborated a program and only then moved on to the negotiation process. Sometimes, they assumed that one such developed program already incorporated the best strategy to solve the challenge problem and used the idea of others only to complement it. At other times, the distinct outlines of programs and ideas they contained only served as the basis for discussing the best way forward.

\subsection{Reasons to participate}

As previously mentioned, there were a number of reasons why students participated in the Virtual DROIDE Project, the use of robots being the biggest motivational factor. As one of the participants pointed out, "being able to participate in the development of the DROIDE project was undoubtedly a great addition to my programming skills. I had never programmed robots or any other such device that would allow me to see the results take place in the real world, and, as such, I found the project extremely interesting from the outset."

Another reason, though not explicit, points to the visual privacy afforded by the virtual component, that sometimes hinders social presence in online learning communities [21]. This fact was evident in certain situations, especially when some of the participants did not want to add a photo that could identify them, or when they did not focus their image during the video sessions or still when, apparently not having a webcam, they refused one that was offered by the project. This type of behaviour was mentioned and discussed by Palloff and Pratt [22] (see also [23]). Some of the participants came to know each other in person only at the final meeting, at the end of the project, as the following statement given by of one of the participants illustrates: "Interesting. People are completely different in person than they are on the net. The virtual experience is very different."

The defining characteristic of participation is the possibility of developing a certain identity through relationships built on participation [24]. Participation is a complex process that combines doing, talking, thinking, feeling and belonging in which there is full involvement, covering the body, mind, emotions and social relationships [10]. The image that an individual has of himself, as well as the one that others make of him, also passes through the image conveyed by the visual aspect. Thus, visual privacy could be important to, resorting to anonymity provided by the concealment of characteristics made possible in a virtual interaction, develop an identity of participation free of inhibiting factors.

The development of self-confidence seems to be another implicit reason for participation in the project. As expressed by 
one of the participants, his involvement in the project "was a good experience. I did not have so much confidence.”

\subsection{Forms of participation}

Lave and Wenger [8] introduced the term legitimate peripheral participation and associated learning to participation, highlighting communities of practice, because these are the places where they learn through participating and vice-versa, having also brought to the fore that the legitimacy of participation comes from involvement in what is proper of practice and not just of the learning that results from it.

It is important to note that the term "peripheral" refers to a position that stimulates the desire to become a full participant, which in turn enables power, determines the path of learning and defines the participant's identity [25].

For these authors, there are three dimensions of learning as participation: the legitimacy of participation, which establishes belonging to the group, the peripherality of participation, which defines the position in the social world as a result of modification of perspectives and positions throughout the learning process, and the legitimacy of periphery, which involves power relationships.

The character of the periphery can be legitimated through access to a growing participation, a situation that attributes power, or there may also be legitimacy to prevent further involvement in participation, thereby maintaining a peripheral position and preventing access to power.

Looking beneath these three dimensions, the group of young people who took part in this study initiated a process of belonging to a social group, that of the Virtual DROIDE Project's community, which defined them as belonging to this group and gave legitimacy to their participation. The trajectory taken, along with assumed positioning in the community throughout the learning process, was due to the involvement and perspectives of everyone in the community, thus becoming a complex course, involving each participant in a distinct manner.

The challenge problems, in order to be completed, required that the robots were properly programmed in the language previously negotiated with the group. Beginners in the art of programming did not start their activity trying to build more elaborate programs, but began to develop small programs, whose complexity evolved as a result of different relationships offered by the evolution of their learning process, making room for repositioning in the community. As an example, the following excerpts, relating to virtual meetings held on three different dates, in a range lower than one month, show part of the learning process of one participant, identified here as Toby, and the change in his position within the community.

\section{January 11th meeting}

Craig: I think that building the robot is the complicated thing.

Toby: I think the programming is more complicated.

Craig: Do you know what functions are?

Toby: I don't think so.

January 26th meeting
Craig: Send me the whole code of your project.

Toby: $O K$.

Craig: It is $O K$, but it could be better.

Toby: Yes, it must be because of the back wheel, I don't know.

Craig: It's almost perfect, it just needs some adjustments.

\section{February 1st meeting}

Craig: I'm creating a new project.

Toby: It's not necessary.

Craig: I want to create one from scratch.

Toby: OK, whatever you want to.

Toby: void setLightSensor(int port)

Sets a light sensor at the given port. Parameters: port The block sensor port must be one of the following: 1,2,3,4.

Craig: That's to turn it on right?

Craig: It gets confusing over Messenger.

Toby: Copy it somewhere else so you'll understand it better.

Craig: What's important is the colour of the dot, it can't be neither black or white.

Toby: Yes, we'll use red or something.

Craig: Do you know which port connects this sensor?

Toby: 3 .

Craig: int getLightValue(int port), I think that's what we must use.

Toby: Yes, so we know the value of the red.

Toby: bool isBetween(int port, int min, int max). I think this is what we have to use so it stops counting the distance.

Craig: I haven't seen that one but you're right, it's better, it simplifies things.

Toby: If the value that it reads is the same it keeps counting the distance.

(...)

Toby: You don't understand.

Craig: Explain.

Toby: What I'm saying is that before the project we need to put a function that reads the frequency and then we put the robot in a red thing.

Craig: No, the frequency of red is always between $405-480 \mathrm{~Hz}$, approximately.

Toby: But it can change a bit depending on the sensor, luminosity.

Craig: But how you were doing it, the test begins when you put down the robot, you can't pick it up again. 
Toby: Yes, but now we could make the robot read the frequency and then use that frequency in the challenge.

Analysing the trajectory of the participant Toby, it is observed that, as time passed, his self-confidence developed, as evidenced in the arguments and assertions transcribed above, demonstrating his growing participation and subsequent learning.

For Wenger [10], participation is not equivalent to collaboration, for it shapes the experience of each person, as well as the community in which such person is placed, transforming both, and with participation, in this sense, being a source of identity.

As for the third dimension mentioned above, still analysing the participation of Toby, his move to a more peripheral position was notorious particularly when the element Richard began to participate in virtual meetings. Here, it is important to clarify the situation of the latter within the group dynamics. Although Toby initially maintained strong interaction with Craig, as evidenced in the previous three partial transcripts of the meetings held virtually, Richard was Craig's classmate and attended the same school and, therefore, had a different relationship.

As stated by Fernandes [26] in regard to the legitimacy of peripherality, this may or may not confer power, permitting or preventing articulation and exchange at the core of communities of practice, which raises some questions: Would the temporary removal of Toby be a way to tell who Richard was and assess the level of their interventions? Would such change bring to a more peripheral participation as the result of intimidation, in recognizing Richard as someone with more knowledge or because Richard nurtured a different relationship with Craig? Was it to see how the meeting would take place without his active participation? Or was it simply to allow more coordination between them and thus promote greater exchange in the community? Unfortunately, due to the complexity of the vast space of identities partially hidden by the barrier provided by the virtual component, many questions, such as those mentioned above, remain unanswered.

However, it is necessary to mention that are the experiences of participation and non-participation, constantly influenced by each other, which make a learning experience important. Wenger [10] highlights two cases of interaction between participation and non-participation: the case of peripherality, in which participation is predominant, and in which nonparticipation is an enabling factor of participation, and the case of marginality, in which non-participation predominates, that prevents full participation.

The distinction between these two cases, that is, the fact of non-participation becoming peripheral or marginal, depends on the relationships of participation defined by the trajectories that lead to non-participation becoming collaborative or problematic. To clarify this difference, Wenger [10] identify four main categories of participation: full participation (accepted by the group), full non-participation (foreign to the group), peripherality (participation made possible by non-participation, whether it leads to full participation or remains on a peripheral trajectory), and marginality (participation limited by nonparticipation, whether it leads to not being a member or to a marginal position).

For example, when a newcomer joins a community his non-participation is a way of learning, in order to reach full participation. However, a veteran may remain in a position of marginality despite being fully integrated, simply because the forms of non-participation that force him to remain in a marginal position are deeply rooted in the community's practice. This is the case, for example, of children within families, who often remain in a marginal position whilst on the way to becoming adults because their parents do not see them as such.

These combinations between participation and nonparticipation reveal the power of individuals and communities, because they define the influences and relationships that may have with the rest of the world. Wenger et al. [15] state that many subscribers to discussion lists and forums rarely or never interact with the group tending only to read messages sent by others. These readers, known as lurkers in Internet culture, are legitimate peripheral participants. Virtual communities of practice provide learning opportunities for those members who are on the periphery, who often end up bringing such learning to other communities.

In the case of the Virtual DROIDE community, an example of this peripheral participation is the course of action taken by the member identified here as Sam, who assumed the position of lurker in most of the virtual meetings. This participant was in the final year of secondary school Information Technology course and was taking an internship in a company during the development of the project, and therefore was no layman on the subject. Regardless, as he chose not to install the adopted programming platform at the outset, he remained essentially in a peripheral position during the first meetings. Later, after installing the DROIDE MLP platform, he contributed effectively to the solution of two challenge problems. Meanwhile, a physical hard disk malfunction caused him to lose all the programs that he had developed and installed. Thereafter, he returned once again only to assume a position of lurker, only following the other participants' dialogues, having even sometimes chosen not to attend the virtual meetings. However, in the final face-to-face meeting, he took on an active part and clearly demonstrated that he had been following the progress of virtual meetings.

\section{Final considerations}

A pertinent question raised by Wenger et al. [15], concerning practice, has to do with the fact that technology over time may be able to help a community to create a shared context, where its members interact constantly, articulate perspectives, accumulate knowledge and provide access to the stories, tools, solutions and concepts.

In the case of the Virtual DROIDE community, it can be argued that the various technologies that participants dealt with, but above all robots, allowed an ongoing interaction, as well as a strong commitment among the participants, not only within the community but also in other more general communities such as Facebook, and that both the use of robots and the adopted programming platform were important technological 
tools to the learning process performed during the runtime of the project.

It was also found that this type of work stimulated the motivation of participants, an aspect corroborated by Jin et al. [27].

In analysing stakeholder participation, we can verify a dynamic evolution during the project, through the increased use of technical vocabulary of programming and reification of concepts and ideas involved in solving the proposed challenge problems in the form of computer programs, which led to their successful resolution.

Barab and Duffy [28] assert that virtual communities of practice provide authentic learning, because these are obtained and validated within real communities, very different from educational institutions and the simulations and problems presented in their scope, which they call practice fields.

Thus, although these authors consider the activities that combine a practical approach with teaching methodologies based on problems and projects as practice fields, this is obviously not the case with Virtual DROIDE, because it is not a school project, and does not imply any gain in terms of classification, and because of the fact that members can enter or leave it voluntarily.

In fact, the design of the project aimed to set up a non-formal space, with access to some initial artifacts which would generate fruitful discussions by stakeholders, in a manner to make possible the analysis of their participation.

It is necessary to continue research on learning that takes place in virtual spaces, given that the Internet provides access to a huge and rapidly-growing volume of information, which leads to experiencing time, space, social relationships, identities and representation of knowledge acquired in a very different way from that experienced in the school and family environments.

Understanding this reality is important for the proper structuring of new forms of teaching and learning taking place in virtual spaces and only with an appropriate theoretical framework can it be gained. In this sense, the theory of situated learning and the approach of communities of practice constitute an indispensable theoretical support for research on the interactions that occur in these spaces, and the analysis of participation, emphasized in this work, is essential for a deeper understanding of the learning processes that occur within them.

\section{Acknowledgements}

The Virtual DROIDE Project was carried out with resources partially derived from the DROIDE II Project - Robots in Mathematics and Informatics Education, financed by the Portuguese Foundation for Science and Technology, FCT (PTDC/CPECED/099850/2008). The authors would also like to thank Dr. Elsa Fernandes of the University of Madeira for her comments and suggestions on an earlier draft.

\section{REFERENCES}

[1] H. Rheingold. The Virtual Community: Homesteading on the Electronic Frontier, Perseus Books, New York, 1993.

[2] J. Lindsay. Online collaboration - How to start, Educational Leadership, Vol. 74, No. 4, 37-41, 2016.

[3] C. Davis, H. Goodman. Virtual communities of practice in social group work education, Social Work with Groups, Vol. 37, No. 1, 85-95, 2014.

[4] S. Kanbul, H. Uzunboylu. Importance of coding education and robotic applications for achieving 21 st-century skills in North Cyprus, International Journal of Emerging Technologies in Learning, Vol. 12, No. 1, 130-140, 2017.

[5] M. Guzdial, B. DiSalvo. Computing education: Beyond the classroom, Computer, Vol. 46, No. 9, 30-31, 2013.

[6] P. G. Feijóo García, F. De la Rosa. RoBlock - Web app for programming learning, International Journal of Emerging Technologies in Learning, Vol. 11, No. 12, 45-53, 2016.

[7] E. A. Santos. Robots as learning mediators in a virtual community of practice, In Proceedings of the 6th International Technology, Education and Development Conference, 6727-6731, IATED, Valencia, Spain, 2012.

[8] J. Lave, E. Wenger. Situated Learning: Legitimate Peripheral Participation, Cambridge University Press, New York, 1991.

[9] Y. Steinert. Educational theory and strategies for teaching and learning professionalism, In R. L. Cruess, S. R. Cruess, Y. Steinert (Eds.), Teaching Medical Professionalism, 31-52, Cambridge University Press, New York, 2009.

[10] E. Wenger. Communities of Practice: Learning, Meaning, and Identity, Cambridge University Press, New York, 1998.

[11] E. Wenger, R. McDermott, W. M. Snyder. Cultivating Communities of Practice, Harvard Business School Press, Boston, MA, 2002.

[12] E. Wenger, B. Trayner, M. de Laat. Promoting and Assessing Value Creation in Communities and Networks: A Conceptual Framework (Rapport 18), Ruud de Moor Centrum, Open Universiteit, Heerlen, Netherlands, 2011.

[13] V. Farnsworth, I. Kleanthous, E. Wenger-Trayner. Communities of practice as a social theory of learning: A conversation with Etienne Wenger, British Journal of Educational Studies, Vol. 64, No. 2, 139-160, 2016.

[14] K. W. Lai, K. Pratt, M. Anderson, J. Stigter. Literature Review and Synthesis: Online Communities of Practice (Report), Ministry of Education, Wellington, New Zealand, 2006.

[15] E. Wenger, N. White, J. D. Smith. Digital Habitats: Stewarding Technology for Communities, CPsquare, Portland, OR, 2009.

[16] E. A. A. Santos, Contribuição para o Estudo da Aprendizagem da Matemática e da Programação em Comunidades Virtuais de Prática com Foco no Uso de Robots como Mediadores da Aprendizagem [Contribution to the Study of Mathematics and Programming Learning in Virtual Communities of Practice with Focus on the Use of Robots as Learning Mediators], Doctoral Thesis, University of Madeira, Funchal, Portugal, 2013. 
[17] H. G. Pestana. Droide MLP - NXT Software Development Kit, Master's Thesis, University of Madeira, Funchal, Portugal, 2008.

[18] O. R. G. Figueira. DRoIDE MLP: Potencializando a Plataforma [DROIDE MLP: Enhancing the Platform], Master's Thesis, University of Madeira, Portugal, 2008.

[19] J. L. Rodríguez Illera. Comunidades virtuales, práctica y aprendizaje: Elementos para una problemática, In J. L. Rodríguez Illera (Ed.), Comunidades Virtuales de Práctica y de Aprendizaje, 11-23, Publicacions i Edicions de la Universitat de Barcelona, Spain, 2008.

[20] R. Nason, E. Woodruff. Online collaborative learning in mathematics: Some necessary innovations, In T. Roberts (Ed.), Online Collaborative Learning: Theory and Practice, 103-131, Information Science Publishing, Hershey, PA, 2004.

[21] K. Kear, F. Chetwynd, H. Jefferis, Social presence in online learning communities: the role of personal profiles, Research in Learning Technology, Vol. 22, 19710, doi:10.3402/rlt.v22.19710.

[22] R. M. Palloff, K. Pratt. Building Online Learning Communities: Effective Strategies for the Virtual Classroom (2nd ed.), JosseyBass, San Francisco, CA, 2007.
[23] R. Palloff. Confronting Ghosts: Lessons in Empowerment and Action, Doctoral Dissertation, Fielding Graduate Institute, Santa Barbara, CA, 1996.

[24] F. Al-Shahrani, H. Mohammad. Conceptual model of successful educational online community of practice for Kingdom of Saudi Arabia, International Journal of Emerging Technologies in Learning, Vol. 9, No. 9, 4-10, 2014.

[25] C. Greenhow, B. Robelia. Informal learning and identity formation in online social networks, Learning, Media and Technology, Vol. 34, No. 2, 119-140, 2009.

[26] E. M. S. Fernandes. Aprender Matemática para Viver e Trabalhar no Nosso Mundo [Learning Mathematics to Live and Work in Our World] (in Portuguese, English abstract), Doctoral Thesis, University of Lisbon, Lisbon, Portugal, 2004.

[27] L. Jin, Z. Wen, N. Gough. Social virtual worlds for technologyenhanced learning on an augmented learning platform, Learning, Media and Technology, Vol. 35, No. 2, 139-153, 2010.

[28] S. Barab, T. M. Duffy. From practice fields to communities of practice, In D. H. Jonassen, S. M. Land (Eds.), Theoretical Foundation of Learning Environments, 25-55, Lawrence Erlbaum, Mathwah, NJ, 2000. 